\title{
CONTOS MOÇAMBICANOS: COMO ESCREVEM A HISTÓRIA DE SEU PAÍS? ${ }^{1}$
}

\author{
Mozambican Short Stories: \\ How do they write the history of their country?
}

Jeferson de Moraes JACQUES

Pontifícia Universidade Católica do Rio Grande do Sul

jeferson.montag@gmail.com

https://orcid.org/0000-0003-0160-9494

Luís Alberto dos Santos PAZ FILHO

Pontifícia Universidade Católica do Rio Grande do Sul

luis.alberto@acad.pucrs.br

https://orcid.org/0000-0003-4667-8186

RESUMO: Narrativas moçambicanas escrevem a história do país, durante e após seu período colonial. A fim de analisar tal processo, será feita uma breve revisão sobre a colonização e seus modos de instauração e manutenção; e o processo de descolonização e as principais consequências, como os conflitos internos sobre um território culturalmente fragmentado e cuja população encontra-se há tempos fragilizada. Neste complexo contexto, a literatura contribui para formação de uma identidade nacional de Moçambique. Livros como Contos africanos dos países de Língua Portuguesa(2010)ajudam a popularizar, no ambiente escolar brasileiro, produções feitas em países africanos já independentes. Por meio de aporte teórico de Frantz Fanon (1968), Homi Bhabha (1998), Jane Tutikian (2006), José Luís Cabaço (2007) e Marçal Paredes (2014),será feita uma breve análise de contos dos três autores moçambicanos presentes no supracitado livro de 2010: O dia em que explodiu Mabata-bata, de Mia Couto, que exemplifica as privações e os perigos aos quais estiveram submetidas muitas crianças durante o período colonial; As mãos dos pretos, de Luis Bernardo Honwana, sobre a exposição da criança à reprodução de discursos racistas pelos adultos; e $O$ enterro da bicicleta, de Nelson Saúte, que apresenta, além do realismo animista, as mortes motivadas por disputas políticas.

PALAVRAS-CHAVE: Descolonização; Identidade; Literatura; Moçambique.

\footnotetext{
${ }^{1}$ O presente trabalho foi realizado com apoio da Coordenação de Aperfeiçoamento de Pessoal de Nível Superior - Brasil (CAPES) - Código de Financiamento 001.
} 
ABSTRACT: Mozambican narratives write the country's history during and after Colonial times. In order to analyze this process, we will present a brief overview about the colonization as well as its institution and maintenance method. Subsequently, we will discuss about the decolonization process and its main consequences such as the internal conflicts about a culturally fragmented territory whose population has been vulnerable for a long time. In this complex context, the literature contributes to the formation of a national identity in Mozambique. The book Contos africanos dos países de Língua Portuguesa (2010) helps productions from independent African countries to become popular in Brazilian school setting. By means of theoretical foundation by (1968), Homi Bhabha (1998), Jane Tutikian (2006), José Luís Cabaço (2007) e Marçal Paredes (2014), we will carry out a brief analysis on the following short stories by the three Mozambique authors which are present in the above-mentioned book: $O$ dia em que explodiu Mabatabata by Mia Couto exemplifies the deprivations and danger suffered by many children in colonial times, As mãos dos pretos by Luis Bernardo Honwana discusses about children exposure to racist speech by adults, and $O$ enterro da bicicleta, by Nelson Saúte, presents an animist realism and the deaths motivated by political conflicts.

KEYWORDS: Decolonization; Identity; Literature; Mozambique.

\section{INTRODUÇÃO}

Um modo comum de colonização consiste no deslocamento de um grupo de determinada região para outra, com intuito de povoar e/ou extrair riquezas de todo tipo, da fauna e da flora: minerais, vegetais ou animais, para uso ou comercialização. Em lugares já povoados, esse ato exerce diversos tipos de violência, tanto física como social e psicológica: a força do colonizador atuará no sentido de fazer prevalecer suas crenças e costumes, bem como a ideia de que seu território é melhor e seu estilo de vida, superior.

Em seu livro Os condenados da terra, publicado originalmente em 1961, o filósofo Frantz Fanon fala sobre esse processo que, com o tempo, passa a possuir estruturas fortes e a atuar no psicológico da população, de modo que não é rara a internalização da ideia de que o colonizador, visivelmente bem-sucedido, seja um ideal de ser, vestir-se e comportarse.

A cidade do colonizado é uma cidade acocorada, uma cidade ajoelhada, uma cidade acuada. [...] O olhar que o colonizado lança para a cidade do colono é um olhar de luxúria, um olhar de inveja. Sonhos de posse. Todas as modalidades de posse: sentar-se à mesa do colono, deitar-se no leito do colono, com a mulher deste, se possível. O colonizado é um 
invejoso. [...] É verdade, não há um colonizado que não sonhe pelo menos uma vez por dia em se instalar no lugar do colono (FANON, 1968, p. 29).

Ao se pensar nos processos de colonização, torna-se impossível não refletir acerca das consequências e impactos dessa narrativa de opressão sobre os modos de perceber e compreender o que é ser nacional. De acordo com José Luís de Oliveira Cabaço, em sua tese Moçambique: identidades, colonialismo e libertação (2007), no caso de Moçambique, há de se pensar, de antemão, em dois fatores: “[...] a divergência na concepção das relações a manter com os colonizados e o distanciamento da guerra por parte da sociedade civil branca, cujo denominador comum é o privilégio" (CABAÇO, 2007, p. 363). Segundo o autor, reside nesses dois aspectos o conflito que terá desenvolvimento no decurso da guerra colonial.

Assim, indagar sobre a (re)construção de identidades a partir do ponto de vista do colonizado é pensar a respeito dos modos de representação que ele projeta, percebe e visa a elaborar. A identidade individual é permeada por processos que buscam dar conta de uma identidade coletiva e nacional. Mas, de que forma seria possível redirecionar as maneiras de se perceber uma vez um território que foi colonizado? Há como desvencilharse por completo das amarras históricas da imagem embutida pelo colonizador?

Um processo de descolonização, momento em que o colonizado luta para reaver aquilo que era seu por direito, começa paulatinamente, e nem sempre de modo conciliador, organizado e passivo.

Vários países da África, a exemplo do Brasil, foram colonizados por Portugal, porém, seus processos de independência tiveram início no século XX. Conforme Jane Tutikian, em Questões de identidade: a África de língua portuguesa:

É a partir de 1946, com a criação da Casa dos Estudantes do Império (CEI), cuja origem está na Casa dos Estudantes de Angola, em Lisboa, que se organiza a consciência libertadora. Funda-se, neste mesmo ano, o Centro de Estudos Africanos e, seis anos depois, o Movimento Anticolonial, onde surgem os primeiros líderes dos movimentos de libertação. Na clandestinidade, são formadas, nas colônias africanas de língua portuguesa, as primeiras organizações políticas, como o Movimento pela Libertação de Angola (1953), Frente de Libertação de Moçambique (FRELIMO), entre outros. Foram, enfim, esses agrupamentos que constituíram o grande movimento de conscientização 
nacional e que empreenderam a luta pela libertação, na maioria das vezes com fortes conflitos e com características peculiares a seu povo e seu território (TUTIKIAN, 2006, p. 38).

Embora ideias de independência já circulassem entre a população moçambicana durante a década de 1950, na década seguinte é que começaram as lutas armadas até a independência, que aconteceu em 25 de junho de 1975. Uma das dificuldades apontadas por Fanon foi o comportamento dos intelectuais, cujos pensamentos podem estar consoantes, em maior ou menor medida, com as ideias do colonizador:

Para assimilar a cultura do opressor, e aventurar-se nela, o colonizado teve de fornecer garantias. Entre outras coisas, teve de fazer suas as formas de pensamento da burguesia colonial. Isso se verifica na incapacidade do intelectual colonizado para dialogar. [...] $\mathrm{O}$ risco permanente que o espreita é então o de fazer populismo. [...] Objetivamente, o intelectual neste período se comporta como um oportunista vulgar. [...] no início de sua coabitação com o povo, privilegia o detalhe e chega a esquecer a derrota do colonialismo, o objeto mesmo da luta. Arrastado pelo movimento multiforme da luta, tende a fixar-se em tarefas locais, levadas por diante com ardor, mas quase sempre com exagerada solenidade. Nem sempre vê o todo (FANON, 1968, p. 37).

Assim, Fanon ressalta que uma descolonização não é uma solução mágica para problemas de toda ordem que acompanham a população. Se o colonizador "[...] tira a sua verdade, isto é, os seus bens, do sistema colonial [...]”, isso é um ato violento, e o autor acredita que, sendo assim, será necessário um enfrentamento na mesma proporção, pois a descolonização "[...] é o encontro de duas forças congenitamente antagônicas [...]” (1968, p. 26). Além da tomada de controle sobre o próprio território, é preciso reaver a autonomia sobre a própria política e a economia, antes geridas pelo colonizador. Neste processo, podem existir divisões internas, grupos poderão entrar em conflito entre si para estar no controle, o que pode levar a sangrentas guerras civis mesmo após a independência, como aconteceu em Moçambique.

Haverá crise econômica e política, mas haverá, também, uma crise de identidade. Supostamente, sem a presença pessoal do colonizador a ditar as regras, uma identidade própria deverá ser construída em um local que, devido às heranças deixadas pelo colonizador, está debilitado e fragmentado em vários sentidos. De acordo com Cabaço, 
Em Moçambique, a guerra foi rapidamente racionalizada e incorporada nas estruturas de pensamento dos colonos. $\mathrm{O}$ aparente confinamento do teatro de guerra ao planalto dos Macondes e ao Niassa - regiões "remotas", sem interesse econômico, escassas de população branca serenara os ânimos da sociedade civil que logo regressou à mesma dolce vita colonial, retomando suas "tarefas" de ganhar dinheiro e viver bem (CABAÇO, 2007, p. 367).

Sob esta perspectiva, pode-se pensar na formação de uma identidade nacional como um processo altamente simbólico: é preciso assumir o controle dos poderes de representação para que se reelabore uma nova visão de mundo sobre si mesmo e que será, em última instância, lançada ao resto do mundo. Aqui, pensa-se o papel fundamental da cultura como agente de transformações e ressignificações: as manifestações artísticas e populares erguerão os novos pilares que sustentarão o imaginário nacional - quem somos, como somos, o que falamos e como falamos, o que buscamos e diversas outras diretrizes; mas também leva-se em consideração o papel desempenhado pela "elite branca" colonizada,que, no caso de Moçambique, tratou de seguir sua vida "normalmente", relegando à parcela negra da sociedade os encargos da opressão, violência e desigualdade.

Homi Bhabha, em seu livro O local da cultura, fala sobre a construção de identidade e diz que ela não é feita unicamente a partir de características individuais, tampouco a partir de uma reedição do passado pré-colonização ou de qualquer outro momento estático: ela se dá no movimento, na soma das trocas das diferenças culturais, que irá constituir "[...] novos signos de identidade e postos inovadores de colaboração e contestação, no ato de definir a própria ideia de sociedade" (BHABHA, 1998, p. 20). Assim, aquilo que constitui a identidade não irá partir de premissas básicas de determinação, como "classe" e "gênero", mas desloca-se para questões mais amplas, como a própria "consciência do sujeito" quanto a "[...] raça, gênero, geração, local institucional, localidade geopolítica, orientação sexual [...]” (BHABHA, 1998, p. 19-20). A este espaço de trocas culturais, que existe na fronteira, o autor denomina "entre-lugar". É na troca cultural que as populações buscarão uma identidade enquanto nação e registrarão, através da literatura, seus saberes, seu modo de ver e sentir o mundo e aquilo que miram para seu próprio futuro. Por meio da ficção, a história, antes contada pelo olhar do colonizador europeu, passa a ser registrada pelo colonizado e divulgada em outros países, mesmo que nem sempre com visibilidade e regularidade suficientes. 
Houve, no Brasil, durante o século XX, um notável apagamento do continente africano dos livros escolares. Na mesma época em que se estudava história, descobertas, modos de vida e culturas de povos das Américas, para o continente africano ficou reservada apenas a informação de que era o lugar de onde foram trazidas as pessoas que foram escravizadas.Com isso, pouco se estudou, nas escolas brasileiras, as culturas dos países africanos: suas histórias, suas religiões, suas cosmovisões e suas lendas.

Conforme Cruz e Pereira (2016), as relações entre o Brasil e o continente africano se intensificaram a partir das transformações sociais e políticas resultantes das lutas anticolonialistas da década de 1960. Houve, no Brasil, algumas publicações de autores de países africanos, como As Sementes de Liberdade (1965), de Manuel de Santos Lima; Tempo Angolano em Itália (1963), de Fernando Costa Andrade; e uma antologia organizada por João Alves das Neves, Poetas e Contistas Africanos (1963). Na década seguinte, a editora Nova Fronteira publicou uma coleção chamada Romances da África, com obras de autores como Emamnuel Dongala, Ferdinand Oyono e Amos Tutuola. No mesmo período, a Editora Codecri também chegou a publicar autores africanos, notavelmente Poemas de Angola, de Agostinho Neto. Porém, tais publicações, mesmo significativas para aquele contexto, obtiveram pouca repercussão junto ao público. A iniciativa seguinte, mais sistemática e de longo prazo, veio da Editora Ática: Coleção Autores Africanos, publicada entre 1979 e 1991.

Visando a apresentar um mapa literário do continente africano ao leitor brasileiro, a série é composta por 27 obras representativas de três períodos da história de seus países: pré-colonial, colonial e pós-colonial. Para Cruz e Pereira (2016), não há outro projeto que possa superar a série em termos qualitativos, tanto que ela motivou outras editoras a publicar material de autores africanos durante a década de 1990.

Porém, ainda não havia uma inserção massiva de obras de autores africanos no âmbito escolar brasileiro, bem como estudos mais direcionados à história e às culturas de países desse continente, o que motivou a criação das Leis 10.639 e $11.645^{2}$, que tornaram

\footnotetext{
${ }^{2}$ BRASIL. Lei $\mathrm{n}^{\mathrm{o}}$ 11.645, de 10 de março de 2008. Altera a Lei no 9.394 , de 20 de dezembro de 1996 , modificada pela Lei $\mathrm{n}^{\mathrm{o}} 10.639$, de 9 de janeiro de 2003, que estabelece as diretrizes e bases da educação nacional, para incluir no currículo oficial da rede de ensino a obrigatoriedade da temática "História e Cultura Afro-Brasileira e Indígena”. D.O.U., Brasília, DF, n 48, 11 mar. 2008. Seção 1, p. 1. Disponível em: $<$ https://pesquisa.in.gov.br/imprensa/jsp/visualiza/index.jsp?jornal=1\&pagina=1\&data=11/03/2008 $>$. Acesso em: 17 set. 2020.
} 
o ensino de culturas indígenas, africanas e afro-brasileiras obrigatórias nas escolas. Embora tais leis não assegurem por completo um estudo sistemático de tais assuntos, bem como uma leitura aprofundada de obras de autores africanos, vale ressaltar um exemplo de obra recente: Contos africanos dos países de Língua Portuguesa, que é o número 44 da coleção Para gostar de ler, da própria Editora Ática, distribuído nas escolas em 2011, pelo PNBE - Plano Nacional Biblioteca na Escola. O livro é dividido em cinco partes: Moçambique, Cabo Verde, São Tomé e Príncipe, Guiné-Bissau e Angola, e cada uma delas contém contos de autores dos respectivos países, funcionando de modo eficaz para iniciar o leitor em uma literaturas oriundas de locais com uma culturas que ele provavelmente não conhece.Há, no livro, textos auxiliares sobre a história e os processos de independência desses países, com suas motivações e consequências, além de esclarecimentos quanto ao vocabulário dos contos, o que facilita a leitura por parte do leitor que tem pouca intimidade com as expressões utilizadas.

Ao se pensar na potência dos discursos literários como ferramentas para a constituição de identidades nacionais, bem como em sua divulgação em outros continentes, deve-se pensar na constituição do nacionalismo como suporte do pensamento e da expressão da arte que virá. Assim, conforme Cabaço,

[...] foi pela maturação da experiência sofrida, pelo estudo e reflexão da própria história ouvida dos mais-velhos, pelo conhecimento direto e indireto de quanto ocorria noutras paragens, mas, sobretudo pelo agravamento constante da segregação e da violência colonialistas que as novas gerações do após-guerra foram estruturando um pensamento nacionalista (CABAÇO, 2007, p. 390).

O primeiro país apresentado em Contos africanos dos países de Língua Portuguesa é Moçambique. Os três contos que conformam o capítulo de Moçambique são $O$ dia em que explodiu Mabata-bata, de Mia Couto, As mãos dos pretos, de Luís Bernardo Honwana, e $O$ enterro da bicicleta, de Nelson Saúte. Tais textos contam,cada um a seu modo, algo singular da história do país durante e após o período colonial, com ênfase em diferentes violências sofridas pela população nesses períodos, conforme serão apresentados a seguir. 


\section{O DIA EM QUE EXPLODIU MABATA-BATA, DE MIA COUTO}

A história é sobre um menino adotado que vivia em uma região rural e trabalhava como pastor de bois. Todos os dias, levava-os para pastar e tomava conta dos animais até o sol se pôr. Seu maior sonho era frequentar a escola, como as demais crianças da sua idade. Chama-se Azarias e presenciou algo assustador que aconteceu com Mabata-bata, um enorme boi malhado que estava sob seus cuidados:

De repente, o boi explodiu. Rebentou sem um múúú. No capim em volta choveram pedaços e fatias, grãos e folhas de boi. A carne eram já borboletas vermelhas. Os ossos eram moedas espalhadas. Os chifres ficaram num qualquer ramo, balouçando a imitar a vida, no invisível do vento (COUTO, 2010, p. 14).

A explicação do menino para esse acontecimento era sobrenatural: havia sido o ndlati, a ave do relâmpago, que habitava a montanha, "[...] onde se juntam todos os rios para nascerem da mesma vontade da água." (COUTO, 2010, p. 15). O ndlati, em seu vôo incendiado, lançara-se ao solo, atingindo o boi. Ou este pisara em uma "réstia maligna" da ave que ficara no chão. Houve o medo do castigo, caso o menino voltasse com um boi a menos. Seu tio, Raul, ficaria furioso. Portanto, seria melhor fugir a ter que retornar com a manada incompleta.

O evento vivenciado pelo menino remete a resquícios de momentos violentos pósindependência, conforme Chaves:

Em 1975, depois de conflitos com Portugal, declarou-se a independência do país, com o partido socialista FRELIMO no poder. Foi então que Moçambique mergulhou em uma guerra civil entre seus dois principais partidos políticos: FRELIMO e RENAMO (Renovação Nacional Moçambicana) (CHAVES, 2010, p. 134).

Ainda conforme a autora, no texto de apresentação do conto, Mia Couto o publicou originalmente em 1986, quando o país passava por uma guerra civil que durou dezessete anos. O texto revela a real natureza da explosão do boi, bem diferente da crença popular presente na imaginação de Azarias: enquanto este se demorava a retornar com a manada incompleta, dois soldados foram até sua casa falar com seu tio: "Boa noite. Vimos comunicar um acontecimento: rebentou uma mina esta tarde. Foi um boi que pisou." (COUTO, 2010, p. 17). 
Azarias representa a vida de muitas crianças moçambicanas desse período: órfão e criado por uma família que queria dele não mais que o trabalho pastoril, que o priva de frequentar a escola, aprender e criar vínculo com as outras crianças de sua idade:

O serviço arrancava-o cedo da cama e devolvia-o ao sono quando dentro dele já não havia resto de infância. Brincar era só com os animais: nadar o rio na boleia do rabo de Mabata-bata, apostar nas brigas dos mais fortes (COUTO, 2010, p. 17).

Além do risco de severo castigo físico caso não retornasse com os bois, há o recorrente abuso emocional por parte do tio, que zomba de sua triste condição por meio de brincadeiras: "Este, da maneira que vive misturado com a criação há de casar-se com uma vaca" (COUTO, 2010, p. 16). Contudo, nada pode ser pior do que sua vida ser entregue à própria sorte ao ter que pastorear em meio a um território que contém minas terrestres capazes de explodir por completo um enorme boi.

Crianças privadas das condições mínimas de desenvolvimento, saúde e educação são consequências de rupturas políticas malconduzidas e finais de processos de dominação que jamais deveriam ter acontecido. De acordo com Chaves (2010), o autor moçambicano Mia Couto foi ativamente participativo no processo de independência de Moçambique e, além disso, foi um dos compositores do hino nacional de seu país. Em seu conto $O$ dia em que explodiu Mabata-bata, Mia Couto revela, sob o olhar de um africano, um pouco dessa triste realidade social e política, apresentando alguns detalhes da cosmovisão desse país: suas crenças, mitologias e seu jeito de explicar, de modo mágico, fenômenos naturais como chuvas e trovões, tão diferentes nas origens e tradições de cada povo. Segundo Tutikian,

[...] a cultura moçambicana se impõe sobre a racional, dentro do projeto de Mia Couto de resgatar e afirmar suas tradições culturais e, ao mesmo tempo, recontar a história moçambicana reprimida, permitindo sua releitura sob um novo prisma, que não o ocidental, mas através de uma forma ocidental, pela reapropriação subversiva da língua. Assim, Mia Couto desconstrói a realidade colonial linguisticamente, denunciando-a tematicamente (2006, p. 41).

Sob o ponto de vista literário, portanto, o conto de Mia Couto assume uma perspectiva que se alinha ao nacionalismo identitário: os fatos históricos, sob a ótica de 
uma criança, são explicados por meio de acontecimentos da mitologia nacional. Há, sob esta perspectiva, um discurso inaugural da nação como explicação dos acontecimentos nas vidas das personagens. Esse modelo de discurso não é transplantado ou copiado do colonizador. Pelo contrário, a lenda de ndlati é produzida pela própria nação e dá conta de explicar os acontecimentos que nela acontecem. Assim, é possível perceber uma tentativa de se desprender da explicação do colonizador para os fatos do cotidiano, recorrendo-se ao material dos nativos.

\section{AS MÃOS DOS PRETOS, DE LUÍS BERNARDO HONWANA}

Um país africano colonizado, além de ter sérias consequências econômicas, terá que lidar com o racismo instituído e perpetuado, que irá associar a cor da pele do colonizado como inferior à do colonizador. Nesse conto, narrado em primeira pessoa, o leitor acompanha uma criança curiosa que anseia por uma explicação sobre o porquê de as mãos dos negros serem claras, perguntando para várias pessoas diferentes, entre elas um padre, um professor, um entregador da Coca-Cola e sua própria mãe. E o mais curioso são as respostas recebidas: nenhuma lhe satisfaz a curiosidade.

O professor associa os negros a macacos, quando diz que "[...] há poucos séculos, os avós delas andavam com elas [mãos] apoiadas no chão [...]" (HONWANA, 2010, p.24). Associar negros a macacos ainda é uma forma comum de racismo, observável, por exemplo, em eventos de grande presença de público, principalmente esportivos. A pessoa seguinte foi o padre que, mesmo depois de dizer que seus catecúmenos não prestavam para nada e que "[...] até os pretos eram melhores [...]" (HONWANA, 2010, p.24), contraditoriamente diz que as mãos dos pretos eram claras porque eles, “[...]às escondidas, andavam de mãos postas, a rezar" (HONWANA, 2010, p. 24). Aqui, é identificável a reprodução inconsciente de ideias racistas no cotidiano, que contradizem aquilo que, na fala seguinte, diz acreditar.

A pessoa seguinte é Dona Dores, que responde que as claras palmas das mãos dos pretos eram assim para "[...] não sujarem a comida que fazem para seus patrões ou qualquer outra coisa que lhes mandem fazer e que não deva ficar senão limpa." (HONWANA, 2010, p. 24-25), associando, mais uma vez, o negro a uma posição subalterna: a servidão. Porém, a pessoa seguinte, Senhor Antunes, identificado não ao 
acaso como o "entregador da Coca-Cola", responde à criança com uma debochada reescrita do Gênesis bíblico: mantendo a ideia de que Deus criou o ser humano a partir do barro, fez os negros depois, e, para cozê-los, pendurou-os nas chaminés, pois não havia outro lugar. Assim, suas palmas das mãos ficaram claras porque "[...] tiveram que se agarrar enquanto o barro deles cozia [...]" (HONWANA, 2010, p. 25), e riu fartamente com os que estavam em volta. Tal cena remonta a situações comuns de piadas racistas em ambientes familiares e demais rodas de conversa na presença de crianças, o que apenas contribui para a naturalização e manutenção desses discursos violentos.

A pessoa seguinte, Senhor Frias, esperou Senhor Antunes ir embora, e, contradizendo o escárnio da resposta deste, deu outra à criança: a de que Deus fazia os homens e os mandava tomar banho em um lago do céu. Como os pretos teriam sido feitos pela madrugada, e, neste momento, a água do lago era fria, eles “[...] só tinham molhado as palmas das mãos e as plantas dos pés [...]” (HONWANA, 2010, p. 26). Porém, mesmo coma aparente vontade de desconstruir o discurso anterior, Senhor Farias, com a ideia de "banho", ainda comete o ato racista de associar a cor negra da pele à sujeira.

A criança, então, recorre a um livro, e este, também associando a negritude à servidão, diz que as mãos dos pretos eram assim porque estes viveram “[...] encurvados, sempre a apanhar algodão branco [...]” (HONWANA, 2010, p. 26). Após, ela pergunta para Dona Estefânia, que, mesmo querendo contradizer o livro, também incorre na ideia de associar a cor negra à sujeira, dizendo que as mãos dos pretos eram assim por "[...] desbotarem à força, de tão lavadas" (HONWANA, 2010, p. 26).

A curiosidade da criança não havia terminado. Ela pergunta à mãe, que lhe diz que brancos e pretos possuem a mesma cor nas mãos porque Deus com isso quis mostrar que

[...] o que os homens fazem, é feito por mãos iguais [...]se tiverem juízo, sabem que, antes de serem qualquer coisa, são homens. Depois de dizer isso, a minha mãe beijou-me as mãos. Quando fugi para o quintal para jogar a bola, ia a pensar que nunca tinha visto uma pessoa a chorar tanto sem que ninguém lhe tivesse batido (HONWANA, 2010, p. 28).

As lágrimas da mãe provavelmente remetem a lembranças de violências sofridas no período colonial, oriundas da visão racista que ela desconstrói na criança, antes mesmo que esta as possa internalizar. 
O conto de Honwana foi publicado originalmente no livro Nós matamos o cão tinhoso, ainda durante o período colonial, em 1964, em meio aos conflitos que culminaram com a independência de Moçambique em 1975. Ao mesmo tempo que registra os principais modos de perpetuação de racismo naquele período, ainda presentes em diversos países, mira para o futuro: a criança, ainda constituindo sua identidade de pessoa negra e africana, tem sua curiosidade sanada por uma mensagem lúcida de igualdade, e é isso que vai levar consigo até a idade adulta.

De acordo com Marçal de Menezes Paredes, no texto A construção da identidade nacional moçambicana no pós-independência: sua complexidade e alguns problemas de pesquisa (2014),

[...] é correto afirmar a existência de múltiplas identidades étnicas existentes no espaço que durante o período colonial português foi sendo chamado de Moçambique. Contudo, a vinculação de grupos étnicoculturais do período pré-colonial com o espaço político-territorial póscolonial parece ser um trajeto com muitas fragilidades, além de escamotear certa mobilização romântica e historicista do tempo histórico (PAREDES, 2014, p. 139).

Assim, os discursos produzidos acerca das relações entre "raça" e etnia e o desenvolvimento das nações, como é o caso do conto de Honwana, passam a tentar reestruturar a forma como se veem as diferenças: trata-se de não apenas uma diferença física, mas, sobretudo, social. Aborda-se não só uma percepção do racismo histórico e estrutural, mas também maneiras de se produzir novos discursos que combatam as narrativas propositalmente excludentes e opressoras. Ao reescrever as formas de representação, possibilita-se reconstruir imagens e projetar novos símbolos que busquem equidade e dignidade para todas e para todos. Essa perspectiva vai ao encontro de Paredes (2014), que destaca o surgimento de uma busca pelas "moçambicanidades", citando José Craveirinha e sua importante obra $O$ folclore moçambicano e as suas tendências, que reúne textos escritos pelo autor entre os anos de 1955 e 1987. Esse prisma de um caráter nacional que recupera raízes a partir do folclore nacional aponta, no mínimo, para a tentativa de se estabelecer discursos de nacionalidades, isto é, formas de ser moçambicano. Desse modo, a narrativa de Honwana não apaga a visão racista presente nas sociedades, mas aponta para a necessidade de mudança e faz uma tentativa de 
reinscrever a identidade no curso da cultura popular, partindo do material histórico e de uma perspectiva crítica cultural.

\section{O ENTERRO DA BICICLETA, DE NELSON SAÚTE}

"A aldeia foi sacudida com a notícia da morte do deputado [...]” (SAÚTE, 2010, p.30). A morte de um político é a motivação do conto de Nelson Saúte, autor que tinha apenas sete anos de idade quando Moçambique conquistou a independência. $\mathrm{O}$ conto descreve o referido deputado como alguém carismático e de exagerada popularidade, que, por onde passava, sempre cumprimentava seus eleitores, formando grandes filas. Durante a vida, trabalhou até como pastor de gado, mas o que se dizia com ênfase é que fora professor, e muito cedo se envolvera com política, tendo ido para o norte para juntar-se à luta. Voltou apenas após a independência, mas, por entender-se como homem do campo, preferiu permanecer na aldeia em vez de viver na grande cidade.Suas idas ao parlamento eram longas: uma viagem de bicicleta até a vila, onde entrava no ônibus em direção à capital da província; de lá, um avião até a capital do país, onde ficava o parlamento. Em seus regressos, ele não era apenas "[...] motivo de festa na aldeia, mas também de frenesim [...]" (SAÚTE, 2010, p. 30). Era visto, portanto, como um herói da independência:

O deputado repetia fielmente os discursos proferidos na tribuna do parlamento, argumentando sobre as vitórias da revolução, vituperando o inimigo. Os seus olhos cresciam, os gestos eram largos, a sua eloquência transformava-o em uma figura mítica. Quem o ouvisse apenas poderia convencer-se de que estava ali o presidente, fazendo um de seus discursos (SAÚTE, 2010, p. 30).

Porém, o deputado não regressara de sua última viagem.Havia, entre o povo, narrativas de crocodilos que devoravam pessoas desprevenidas, mas a morte do deputado foi atribuída a um leão, mesmo ninguém tendo ouvido falar em aparições de leões naquela região. Mesmo não havendo testemunhas do confronto com o leão, havia histórias que exaltavam a coragem do deputado:

Não fugiu, olhou frontalmente o animal, sem medo de suas jubas e de seus rugidos. Mas não estavam em igualdade de circunstâncias: as forças e armas eram tremendamente desiguais. O leão levou a melhor, tanto 
mais que do homem apenas restou uma bicicleta retorcida e alguns farrapos da sua roupa. A aldeia parou durante dias para os funerais (SAÚTE, 2010, p. 31).

Funerais eram (e continuam sendo) momentos importantes para aquela população, tanto que acreditavam que a alma do falecido só descansaria após esse momento. Porém, mesmo não havendo um corpo para sepultar, a urgência do funeral prevalecia, ainda que enterrassem apenas um de seus pertences: no caso, o que sobrara de sua bicicleta.

Há, pelo menos, dois registros históricos e culturais no conto de Nelson Saúte: o primeiro refere-se à natureza animista comum em narrativas de alguns países do continente africano. Nelas, cenários e objetos, a exemplo da bicicleta, não estão presentes apenas para fins de comunicar e acrescentar informações complementares à narrativa, mas, com as pessoas, são um só, formando um todo vivo:

Os escritores africanos [...] não têm necessidade de preparar terreno para o sobrenatural ou apresentar soluções mágicas para dar ordem à narrativa. [...] Refletem artisticamente um espaço onde o leitor não precisa entrar "de maneira quase mágica", ou se abandonar a ele com "fé poética"; antes, bastaria reconhecer um estatuto real-animista característico da realidade sócio-histórica que dá conteúdo à narrativa (SARAIVA, 2007, p. 6).

O segundo registro aparece de modo implícito. Como parece improvável que o deputado fora devorado por um leão, dada a ausência deste animal naquele ambiente e a falta de testemunhas e provas, a morte do representante popular, naquele contexto póscolonial de guerrilhas, levanta outra hipótese: a de que ele fora raptado por inimigos políticos. Tal hipótese surge ao final do conto, durante a movimentada cerimônia de funeral do deputado, com a chegada de um mensageiro exausto, que fizera de tudo para chegar antes do funeral da bicicleta. Porém, este, com a língua de fora, caiu e desmaiou, tendo morrido ali mesmo, sem que funcionasse qualquer tentativa de reanimá-lo, de modo que sequer conseguira revelar o que lhe trouxera ali. $O$ mensageiro poderia ser uma testemunha ou alguém que tivesse informações sobre o paradeiro do deputado, mas nada pôde ser confirmado devido à sua morte.

Dividido entre dois polos - o do animismo e o do político -, o conto de Saúte metaforiza as relações das identidades sob a perspectiva do pós-colonial: o efeito da 
globalização, que vem aflorando cada vez com mais intensidade as fronteiras de todo o mundo, tem causado diversas questões: é possível conceber ainda uma identidade nacional? Em que medida ela existiria e quais são as influências de outras nações (e, por conseguinte, identidades nacionais) umas sobre as outras? Há um sentido de representação integral e coeso? Ao partir dessas questões, pode-se assinalar duas importantes esferas reconhecíveis na narrativa de Saúte: por um lado, o fator animista contribui para a organização de um mito de fundação nacional. Esse elemento contribui com a jornada identitária de uma sociedade que busca, através da diferença, construir discursos culturais que visem à plena unidade de sentidos de representação. Sob o guarda-chuva da análise animista, há um estilo de vida e um modo de ver o mundo e o sujeito que difere em muito de outros modos presentes no imaginário do Ocidente, por exemplo. O indivíduo e a natureza, em todos os elementos que a compõem, formam uma unidade significativa, e não antitética, como é possível observar em outras nações nas quais o homem, dotado de razão, está no lado oposto superior dos animais, que representam o instinto e a irracionalidade. Saúte apresenta um universo no qual todos os elementos pertencem à ordem Natural. Assim, a ideia de origem (ou nascimento) é única: ao integrar elementos da natureza à mesma ordem que a dos sujeitos, o respeito à vida e à morte alcançam proporções ressignificadas. Por outro lado, o fator político irrompe do plano cosmológico estabelecido e provoca a desestruturação da ordem: o elemento exterior, o mensageiro, perturba o equilíbrio - uma analogia possível ao efeito do colonizador. Deve-se, portanto, de acordo com Paredes,

[...] recusar algumas simplificações ingênuas que postulam a coincidência e mesmo a continuidade entre a construção identitária anterior ao processo de independência nacional e o momento posterior. Mais do que uma recuperação identitária prévia, tratava-se da construção de algo novo e em direção oposta ao passado. Este projeto - e até para fazer o contraste ao tradicional (entendido como supersticioso e "velho") - foram utilizadas compreensões de ordem "científica" no que tange aos objetivos a serem alcançados. O lugar do assimilado neste novo projeto era, desse modo, estratégico (PAREDES, 2014, p. 151). 


\section{CONSIDERAÇÕES FINAIS}

Colonização e descolonização trazem consequências profundas para um país, tanto de natureza econômica quanto cultural. Nesses processos, enfraquecem-se, portanto, a cultura e a identidade do colonizado, que vê suprimidas e diminuídas suas crenças, produções artísticas e até o modo de gerir a sua própria economia, desejando ocupar o lugar do colonizador.

Assim, em virtude dos períodos de guerra civil após a independência, a busca por uma identidade própria e por estabilidade econômica pode levar décadas. Nesse contexto, a literatura possui papel fundamental: enquanto conta e registra momentos que jamais devem ser esquecidos, ela constrói a história. Além disso, traz, ao leitor de outro continente, reflexões sobre assuntos pertinentes e apresenta um diferente modo de ver o mundo, escrito a partir do ponto de vista daquele que um dia já foi colonizado e cuja cultura foi ignorada e subestimada.

Sob tais perspectivas, este trabalho pretendeu esboçar uma trajetória das relações entre a produção de discursos culturais (no caso, literários) e a história de países que enfrentaram e enfrentam processos descoloniais. Para realizar este estudo, optou-se por três contos de três autores cujas perspectivas apresentam modos diferentes de enfrentar os problemas advindos dos processos coloniais, bem como de projetar novas esperanças para a construção de identidades culturais. No conto $O$ dia em que explodiu Mabata-bata, de Mia Couto, pode ser entendido como se dá a consolidação de uma tradição que estabelece novos domínios culturais e reescreve as problemáticas históricas sob a ótica das lendas locais; As mãos dos pretos, de Luis Bernardo Honwana, aborda o racismo estrutural e o sentimento de opressão por ele causado, propondo a reescrita da esperança a partir da renovação dos discursos históricos alicerçados no imaginário popular; por sua vez, o conto intitulado $O$ enterro da bicicleta, de Nelson Saúte, elabora duas formas de perceber o mundo que acabam por se concretizar em um mesmo plano: o animismo, que amplia e reconfigura o universo exegético com o estabelecimento da equidade entre natureza e sujeito; e o discurso do indivíduo político, que historiciza o plano literário, criticando os elementos exteriores que corrompem o cosmos nacional.

Assim, buscou-se instigar reflexões acerca das relações entre literatura e a reescrita da história de algumas nações, que, em última instância, dizem respeito à reescrita de 
identidades que ainda estão porvir.

\section{REFERÊNCIAS}

BHABHA, H. K. O local da Cultura. Tradução de Myriam Ávila, Eliana Lourenço de Lima Reis e Gláucia Renate Gonçalves. Belo Horizonte: Ed. UFMG, 1998.

BRASIL. Lei n 11.645 , de 10 de março de 2008. Diário Oficial da União, Brasília, DF, no 48, 11 mar. 2008. Seção 1, p.1. Disponível em: $<$ https://pesquisa.in.gov.br/imprensa/jsp/visualiza/index.jsp?jornal=1\&pagina $=1 \&$ data $=11$ /03/2008>. Acesso em: 17 set. 2020.

CABAÇO, J. L. O. Moçambique: identidades, colonialismo e libertação. 2007. 475f. Tese de Doutorado - Antropologia social. Universidade de São Paulo, São Paulo, 2007.

CHAVES, R. A mesma língua, outro continente, diversos países. In: CHAVES, R. (Org). Contos africanos dos países de língua portuguesa. São Paulo: Ática, 2010.

CHAVES, R. (Org). Contos africanos dos países de língua portuguesa. São Paulo: Ática, 2010.

CRUZ, C. R.; PEREIRA, M. R. A Coleção Autores Africanos em periódicos: um mapa da África literária. Anais do XV Encontro ABRALIC. 19 a 23 setembro de 2016. UERJ - Rio de Janeiro. Disponível em: <https://abralic.org.br/anais-artigos/?id=1564>. Acesso em: 22 jul. 2020.

COUTO, M. O dia em que explodiu Mabata-bata. In: CHAVES, R. (Org). Contos africanos dos países de língua portuguesa. São Paulo: Ática, 2010.

FANON, F. Os condenados da terra. Tradução de José Laurênio de Melo. São Paulo: Civilização Brasileira, 1968.

HONWANA, L. B. As mãos dos pretos. In: CHAVES, R. (Org). Contos africanos dos países de língua portuguesa. São Paulo: Ática, 2010.

PAREDES, M. M. A construção da identidade nacional moçambicana no pósindependência: sua complexidade e alguns problemas de pesquisa. Anos 90, Porto Alegre, v. 21, n. 40, p. 131-161, dez., 2014.

SARAIVA, S. S. O realismo animista e o espaço não-nostálgico em narrativas africanas de língua portuguesa. Anais do Encontro Regional da ABRALIC, 23 a 25 de julho de 2007 - Literatura, Artes, Saberes. USP - São Paulo, 2007. Disponível em: $<$ http://www.abralic.org.br/eventos/>. Acesso em: 06 jul. 2020. 
SAÚTE, N. O enterro da bicicleta. In: CHAVES, R. (Org). Contos africanos dos países de língua portuguesa. São Paulo: Ática, 2010.

TUTIKIAN, J. Questões de identidade: a África de língua portuguesa. Letras de hoje, Porto Alegre, v. 41, n. 3, p. 37-46, set., 2006.

Recebido em: 24 jun. 2020.

Aceito em: 31 jul. 2020. 